\title{
Experimental Characterization Strategies of Non- Linearity Measurement Exhibitions for The Wideband LNA in IEEE L and S Bands
}

\author{
Pramod K B Rangaiah \\ $\mathrm{PhD}$ student of JAIN University, Electronics Engineering \\ MCT’s RGIT, EXTC Dept, Mumbai \\ Bangalore, India
}

\author{
Kumaraswamy H V \\ Dean CAT, RVCE \\ Telecommunication Dept \\ Bangalore, India
}

\begin{abstract}
In this paper, the test portrayal strategies of nonlinear measurements of wideband LNA exhibitions are simulated. Likewise, significance of the nonlinear estimations has been portrayed unmistakably with microwave LNA operating large signal analysis had been assessed. This work is endeavored to demonstrate the performances of the LNA with AM-AM, AMPM measurements in points of interest and differentiating from the linear measurement regime. The most of the important aspects of LNA will be in linear measurements and furthermore to quantify nonlinear measurements accurately harmonic balance simulator is used. The harmonics up to order 3 and power characteristics are altogether shown with power swept variable. A simulation setup is made to measure the characteristics of LNA by using spectrum rectangular display type with power harmonic components. At last, author designed wideband LNA from the bandwidth $1 \mathrm{GHz}$ to $5 \mathrm{GHz}$ and elaborates how nonlinear measurements changed the way of LNA design to validate and development in microwave frequencies.
\end{abstract}

Keywords- wideband LNA; Nonlinear measurements; microwave and harmonics.

\section{INTRODUCTION}

Microwave amplifiers are fundamental empowering parts for wireless communication systems, broadband, wideband satellite and radars applications. Propelled estimation methods that give precise data on crucial parts of the amplifier dynamics and noise are significant to enhance achievement in the plan and manufacture of present day mobile handsets [1-3]. Microwave amplifiers add noise to the coveted signal delivering corruption of affectability, determination and signal quality in wireless systems. NF is usually decided without the carrier, yet it can likewise be acquired from AM or PM noise spectra and, along these lines, as an element of carrier level [4$6]$.

The Calculations of intermodulation (IM) noise and input power to output power transfer attributes for various distinctive nonlinear amplifiers are observed to be in great concurrence with estimations. The calculations are depending on the deliberate $\mathrm{AM} / \mathrm{AM}$ and $\mathrm{AM} / \mathrm{PM}$ attributes, and incorporate aftereffects of a simulation in the EDA tools like AWR, and diagnostic results in light of displaying the amplifier as a perfect envelope limiter [7].

\section{RESEARCH BACKGROUND AND COLLECTED DATA}

This area depicts about most recent related work done by the analyst on nonlinear measurements, V. Bridier et al.,[8] portrayed of radar power amplifier driven by non-periodic pulsed signal was proposed. The mixer based NVNA can gauge the basic and two harmonics at the same time while utilizing non-periodic radar pulse train prepare permitting measuring time domain waveforms and pulse to pulse measurement within actual radar conditions. The estimation is connected on a S-band 5W GaN on silicon HEMT. Later, [9] measure a non-periodic monotonous radar pulse train as a prepare as an intermittent one was performed. At that point, surprisingly a $20 \mathrm{GHz}$ six port mixers based NVNA ready to gauge three unique frequencies in the meantime is outlined and approved. This instrument permitted us to defeat the imprecision brought about by the successive estimations of the distinctive tones that emerge when the gadget under test show highly unstable pulse to pulse behavior conduct which is regular in radar working conditions. It was conceivable to get the nonlinear conduct of a gadget inside a genuinely nonperiodic predefined pulse train. B. Brown [10], depicted a RF network analyzer, the HP 8753B, which can make nonlinear estimations of amplifiers and mixers. The estimations to be talked about are cleared swept-frequency harmonic distortion, gain compression with power metal calibration, and sweptfrequency conversion loss of a mixer. Moreover, the piece graph of the system analyzer will be inspected with a specific end goal to clarify how these estimations are made. Pramod K B et.al, [11] displayed an examination, setup, outline to quantify nonlinear attributes of LNA besides examination, 
evaluate those estimations in the AWR microwave office Tool. An extensive bit of the basic parts of LNA will be in linear measurements and which is composed, designed and simulated for the ultra-wideband LNA from 3-10GHz.

\section{THE PROPOSED DESIGN}

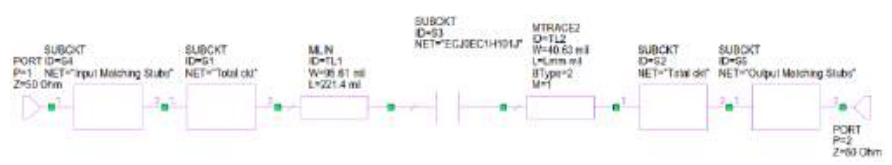

Figure 1. The proposed LNA design Schematic in block form

The above figure 1 is the entire schematic diagram of the proposed design of the wideband LNA. It has obviously indicated schematic comprises of the sub block which is having name (net) from left side to be specific "Input Matching Stubs", "Total Ckt", MLIN, Capacitor and MTRACE2, "Total Ckt" and "Output Matching Stubs". Every last square will be examined obviously one by one with schematic and designs. The reason, limit and capacity of every sub-square will be examined and analyzed in detail advance.

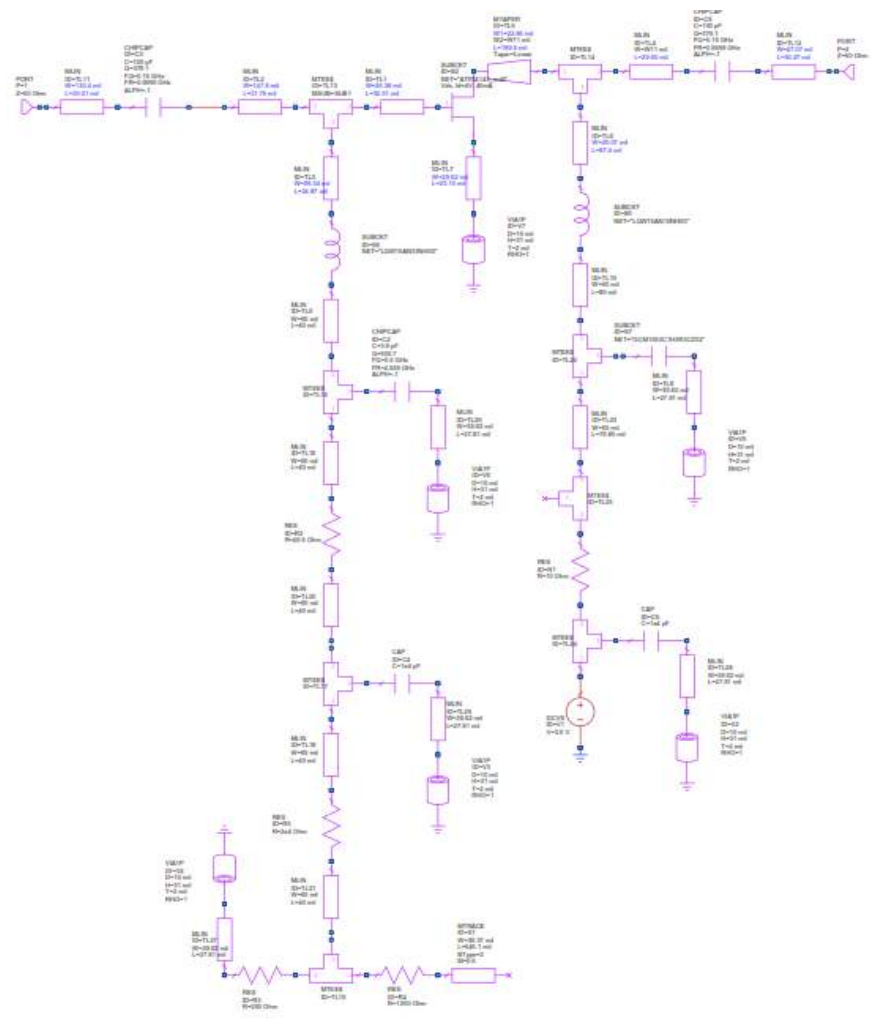

Figure 2. Shows the Sub Block "Total Ckt" of the complete schematic in detail

The above figure 2 is the sub block of the main circuit schematic figure 1. In order to make cascaded LNA is it good practices by the designer to make first single stage LNA circuit and then followed by that same circuit will be duplicated and connected in series side by side. The cascaded 2 stage amplifier will be done by using 2 "Total Ckt" with intermediate matching by using capacitor "ID S3", "MLIN" and "MTRACE2" which is shown in figure 1. LNA parameters are mainly depend on $\mathrm{S}$ parameters which varies with respect to frequency. Also $\Gamma$ in depends on Zin and $\Gamma \mathrm{L}, \Gamma \mathrm{L}$ depends on ZL and $\Gamma I N$. Zin and ZL will be different for different biasing components. Effects of biasing components is also frequency dependent.

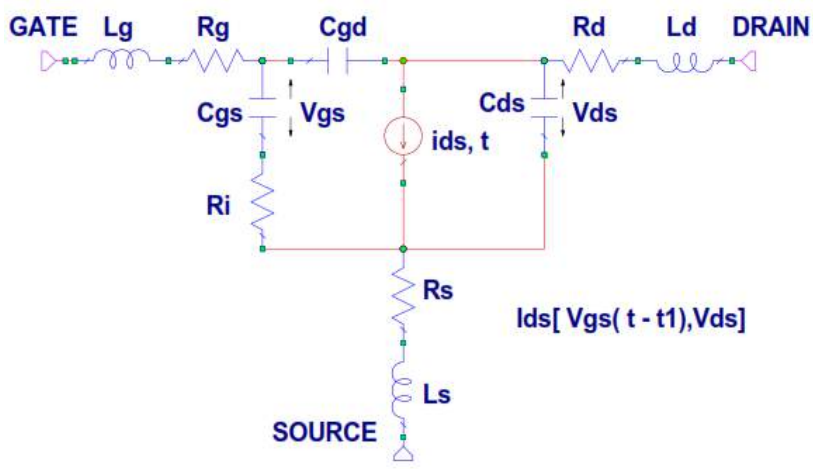

Figure 3. The small signal model of a pHEMT

Cgs and Cgd depends on the biasing voltage because the depletion region changes with the bias .

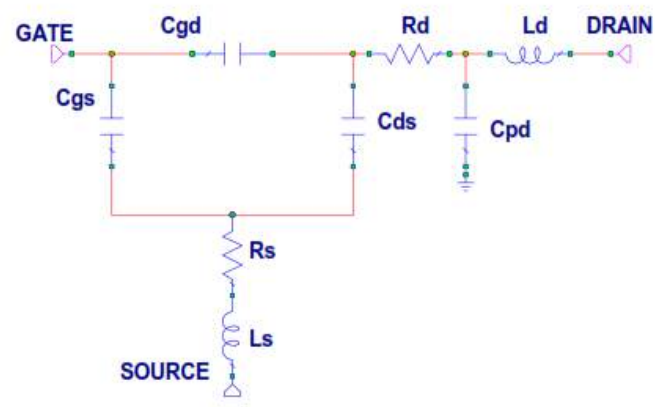

Figure 4. The small signal model of a pHEMT at zero drain bias and gate voltage below pinch-off

The three capacitances $\mathrm{Cg}$, Cs and $\mathrm{Cd}$ are given by triangle-star transformation as given below

$$
\begin{aligned}
& \mathrm{C}_{\mathrm{g}}=\mathrm{C}_{\mathrm{gs}}+\mathrm{C}_{\mathrm{gd}}+\left[\left(\mathrm{C}_{\mathrm{gs}} * \mathrm{C}_{\mathrm{gd}}\right) / \mathrm{C}_{\mathrm{ds}}\right] \\
& \mathrm{C}_{\mathrm{s}}=\mathrm{C}_{\mathrm{gs}}+\mathrm{C}_{\mathrm{ds}}+\left[\left(\mathrm{C}_{\mathrm{gs}} * \mathrm{C}_{\mathrm{ds}}\right) / \mathrm{C}_{\mathrm{gd}}\right] \\
& \mathrm{C}_{\mathrm{d}}=\mathrm{C}_{\mathrm{ds}}+\mathrm{C}_{\mathrm{gd}}+\left[\left(\mathrm{C}_{\mathrm{gd}} * \mathrm{C}_{\mathrm{ds}}\right) / \mathrm{C}_{\mathrm{gs}}\right]
\end{aligned}
$$

Input port and output port impedances can be expressed using $\mathrm{Z}_{11}=\mathrm{R}_{\mathrm{g}}+\mathrm{R}_{\mathrm{s}}+\mathrm{j} *\left[\omega\left(\mathrm{L}_{\mathrm{g}}+\mathrm{L}_{\mathrm{s}}\right)-(1 / \omega)\left\{\left(1 / \mathrm{C}_{\mathrm{g}}\right)+\left(1 / \mathrm{C}_{\mathrm{s}}\right)\right\}\right](4)$ $\mathrm{Z}_{22}=\mathrm{R}_{\mathrm{d}}+\mathrm{R}_{\mathrm{s}}+\mathrm{j} *\left[\omega\left(\mathrm{L}_{\mathrm{d}}+\mathrm{L}_{\mathrm{s}}\right)-(1 / \omega)\left\{\left(1 / \mathrm{C}_{\mathrm{d}}\right)+\left(1 / \mathrm{C}_{\mathrm{s}}\right)\right\}\right](5)$ Input reflection coefficient and output reflection coefficient

$$
\begin{aligned}
& \Gamma_{\text {in }}=\left(Z_{\text {in }}-Z_{0}\right) /\left(Z_{\text {in }}+Z_{0}\right) \\
& \Gamma_{\mathrm{L}}=\left(Z_{L}-Z_{0}\right) /\left(Z_{L}+Z_{0}\right)
\end{aligned}
$$

Equivalent input and output impedances can be expressed in terms of two port $\mathrm{Z}$ parameters. 


$$
\begin{aligned}
& Z_{\text {in }}=Z_{11}-\left[\left(Z_{12} * Z_{21}\right) /\left(Z_{L}+Z_{22}\right)\right] \\
& Z_{L}=Z_{22}-\left[\left(Z_{12} * Z_{21}\right) /\left(Z_{G}+Z_{11}\right)\right]
\end{aligned}
$$

On the premise of the above arrangement numerical conditions unmistakably reliance of $\Gamma$ in and $\Gamma \mathrm{L}$ furthermore $\mathrm{Zin}$ and $\mathrm{ZL}$ on $\mathrm{Cg}$, Cs and $\mathrm{Cd}$ which changes because of progress in biasing conditions.

For the effective outcome, even after fabrication implementations this proposed configuration will be conveyed into two unique forms of the micro strip lines structure.

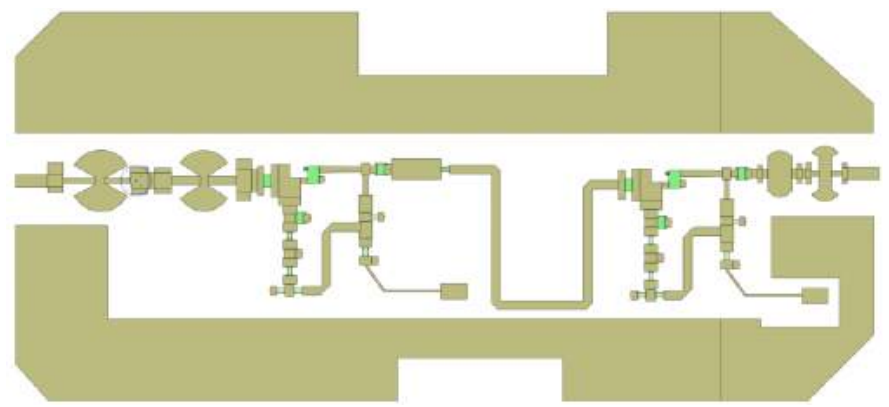

Figure 5. Shows the 2D layout of the complete proposed LNA design

This above figure 5 shows the complete 2D layout and figure 6 shows 3D layout. This is the layout of proposed changes in input matching stubs and output matching stubs for the complete circuit which has displayed in figure 1. To avoid the parasitic fringing effects the metal outer shape has been provided and series vias are provided to remove or unnecessary charges will be grounded immediately

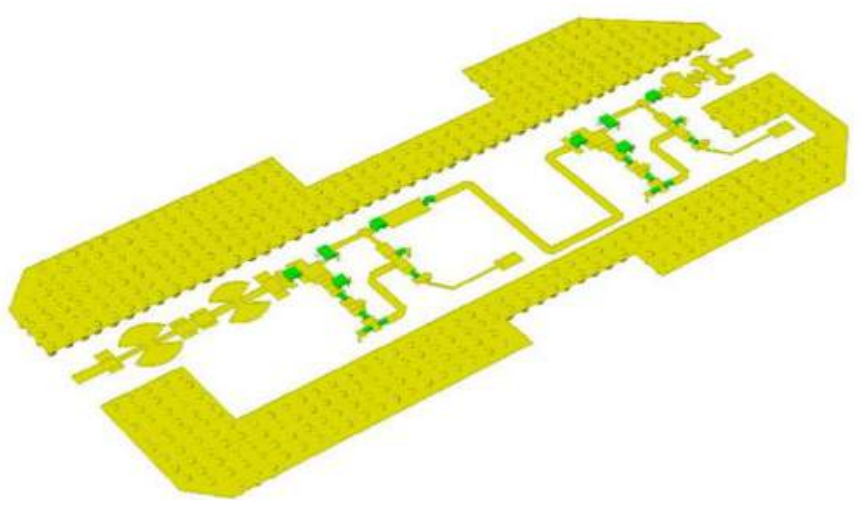

Figure 6. Shows the 3D layout of the complete proposed LNA design

\section{NON-LinEar MEASUREMENTS}

This segment depicts the obtained quantities and the normal estimation approaches. Despite the fact that the non-linear measurements that much fundamental for the LNA in this research proposed design measured to have better clarity [1214]. The first strategy measures all amounts identified with power (scalar quantities) with huge band power meters and the majority of the other vector quantities (reflection coefficients) with a formerly adjusted VNA. As in all open loop control systems, this setup is constrained in light of the fact that the preparatory adjustment decides the nature of the results [15$16]$.

\section{A. AM to $A M$}

In the figure 7 shows the measurement of $\mathrm{AM}$ to $\mathrm{AM}$ with swept power from $-30 \mathrm{dBm}$ to $30 \mathrm{dBm}$ for the proposed design LNA with the specified options. This result shows a sample AM to AM output data file of a 2-port circuit proposed LNA, where Port 1 is the input port and Port 2 is the output port. The input port is exited with variable power supply from $-30 \mathrm{dBm}$ to $30 \mathrm{dBm}$ over all frequency swept.

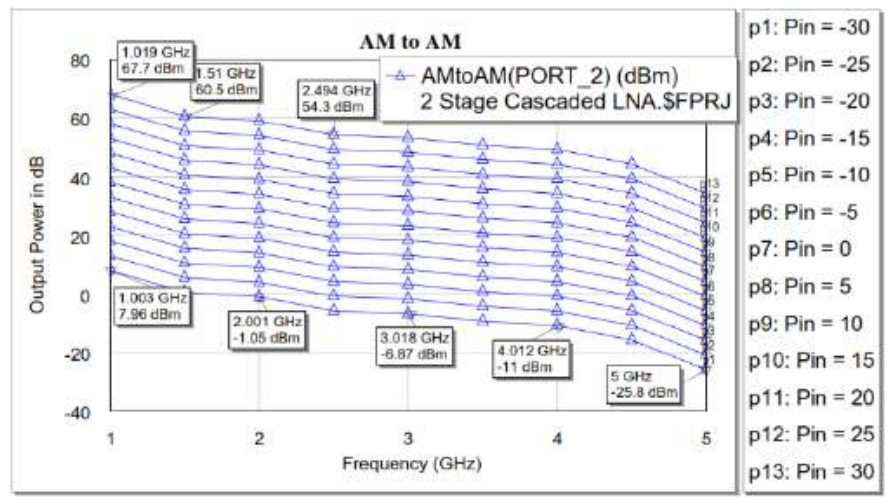

Figure 7. AM to AM response with swept power $(-10 \mathrm{dBm}$ t0 $30 \mathrm{dBm})$ measurements from simulations.

\section{B. AM to PM measurements}

In the above figure 8 demonstrates the estimation of AM to PM with cleared power from $-30 \mathrm{dBm}$ to $30 \mathrm{dBm}$ for the proposed design LNA with the predetermined choices. When Output Data Type is PM, the estimation composes the AM to PM change of the circuit, registering the stage point of the output voltage as a component of power in. where Port 1 is the input port and Port 2 is the output port. The input port is left with variable power supply from - $10 \mathrm{dBm}$ to $15 \mathrm{dBm}$ over all frequency sweep.

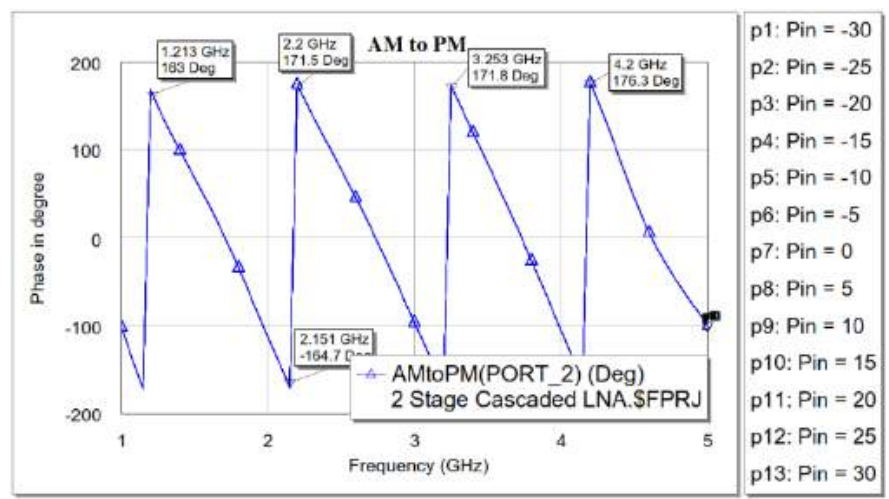

Figure 8. AM to PM response with swept power $(-10 \mathrm{dBm} 1015 \mathrm{dBm})$ measurements from simulations. 


\section{Harmonics}

Harmonics are a numerical method for portraying mutilation to a voltage waveform. The term harmonic alludes to a segment of a waveform that happens at a number different of the essential fundamental frequency.

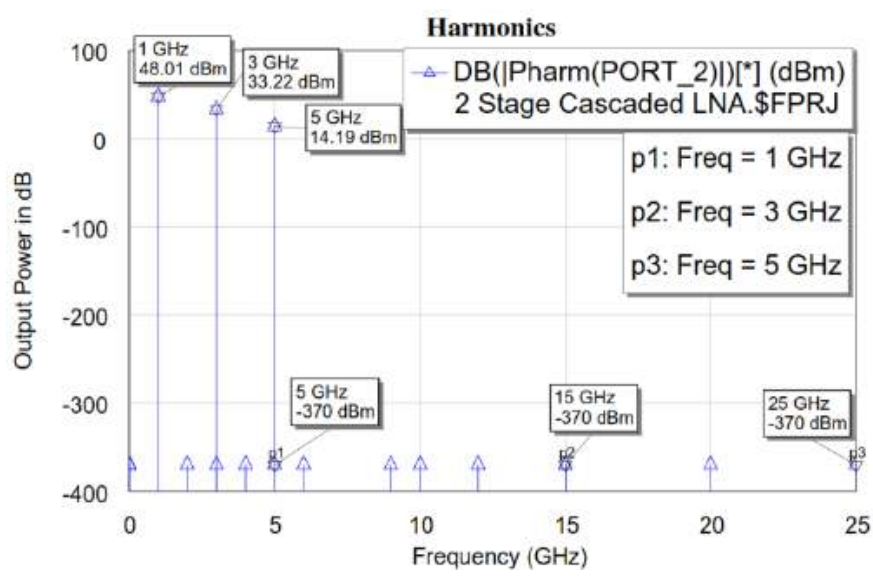

Figure 9. Shows the up to 3rd order harmonics for 3 frequency components 1,3 and $5 \mathrm{GHz}$.

The above figure 9 shows the harmonics responses of the proposed LNA design for up to 3rd order for the three fundamental frequencies 1,3 and $5 \mathrm{GHz}$ and for the input power is $10 \mathrm{dBm}$. The output of fundamental components is around $48,33 \mathrm{dBm}$ but harmonics is $-370 \mathrm{dBm}$. Which concludes that harmonics can be easily filtered out.

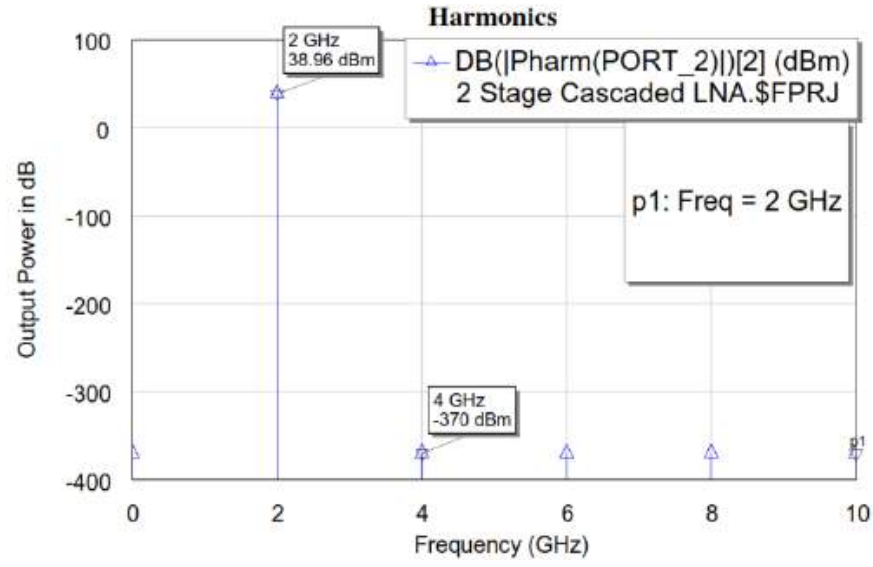

Figure 10. Shows the up to 3rd order harmonics for the frequency components $3 \mathrm{GHz}$

The above figure 10 demonstrates the harmonics responses of the proposed LNA design for up to 3rd order for the fundamental frequency $3 \mathrm{GHz}$ and for the input power is $10 \mathrm{dBm}$. The output of fundamental components is around 33 $\mathrm{dBm}$ but harmonics is $-370 \mathrm{dBm}$. Which presumes that harmonics will be effortlessly filtered out by using buffer filter banks.

\section{Power charactereistcis}

The collective figures 11 to 13 displays the power characteristics of the design LNA.

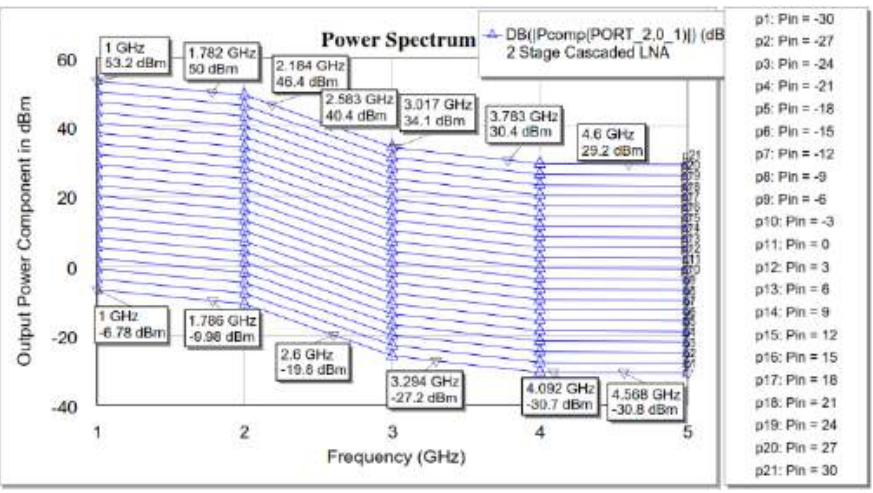

Figure 11. Shows the output power components for the power swept throughout the frequency band

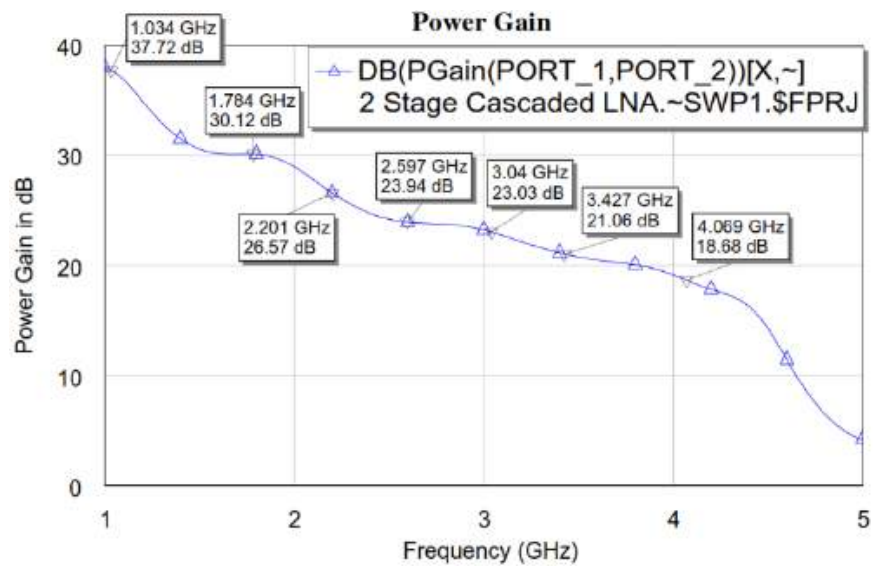

Figure 12. Shows the power gain of the proposed LNA

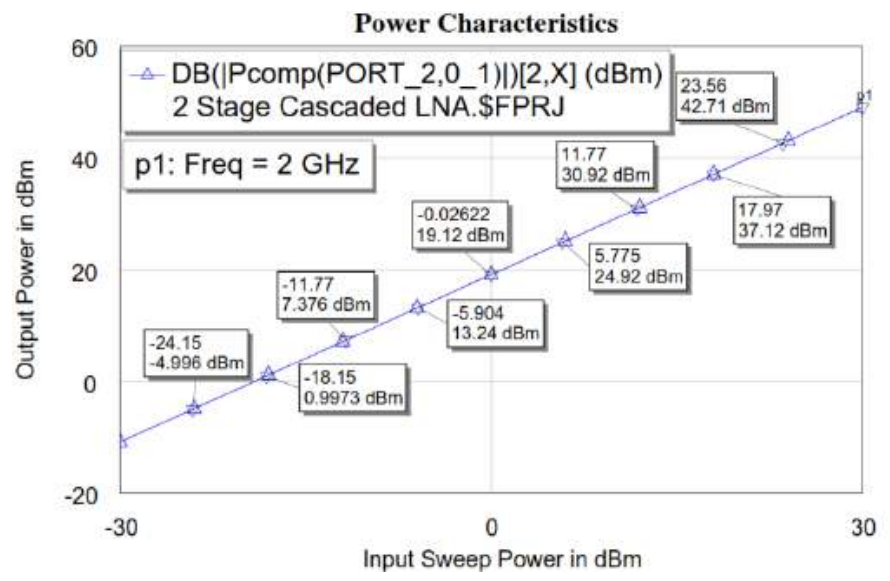

Figure 13. Shows power characteristics linearity test 


\section{LINEAR MEASUREMENTS}

The section includes the linear measurements of the proposed LNA design

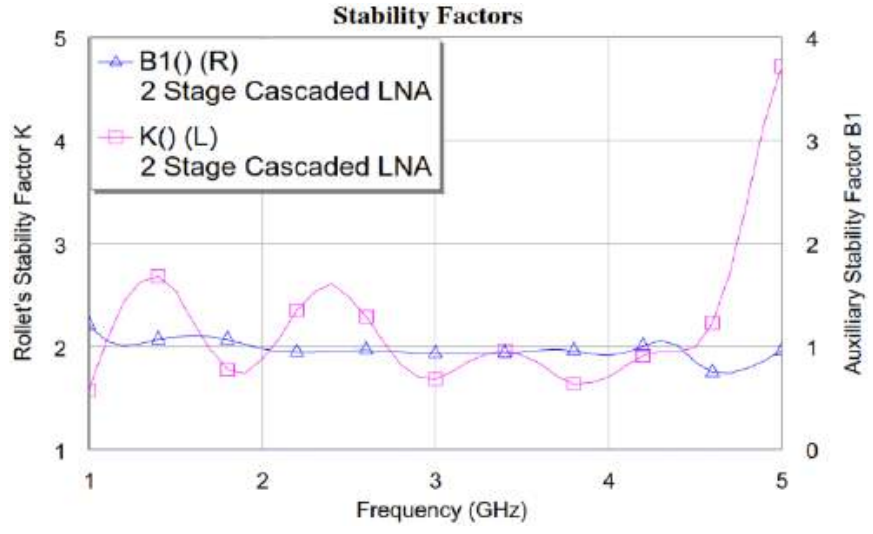

Figure 14. Shows Stability factors: Rollet Factor K and B1 of the proposed LNA design

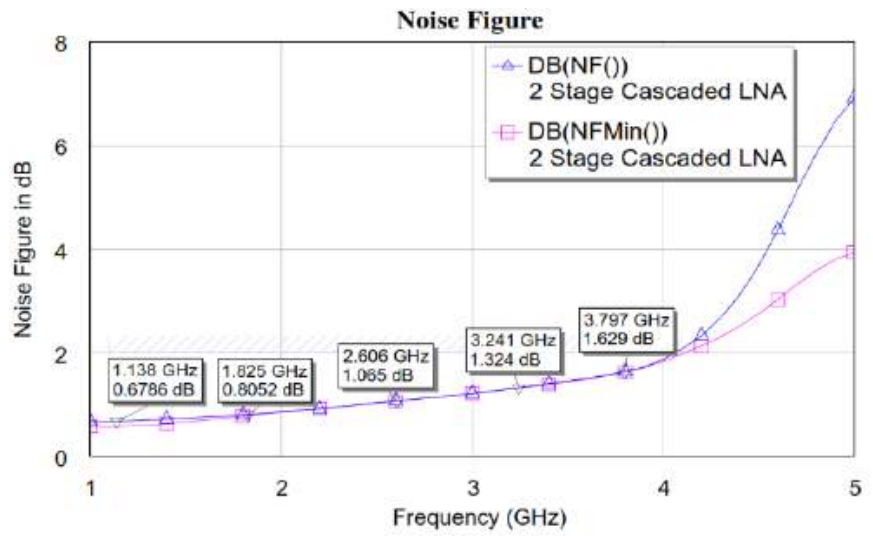

Figure 15. Shows Noise Figure characteristics of the proposed LNA design

The above demonstrated figure 14 shows the stability factors which incorporates Rollet Factors K should greater than 1 and B1 auxiliary factors greater than 0 which is prevailing through the band $1-5 \mathrm{GHz}$. In the figure 15 which is plotted the Noise Figure measurements which is less than $2 \mathrm{~dB}$ up to $4 \mathrm{GHz}$

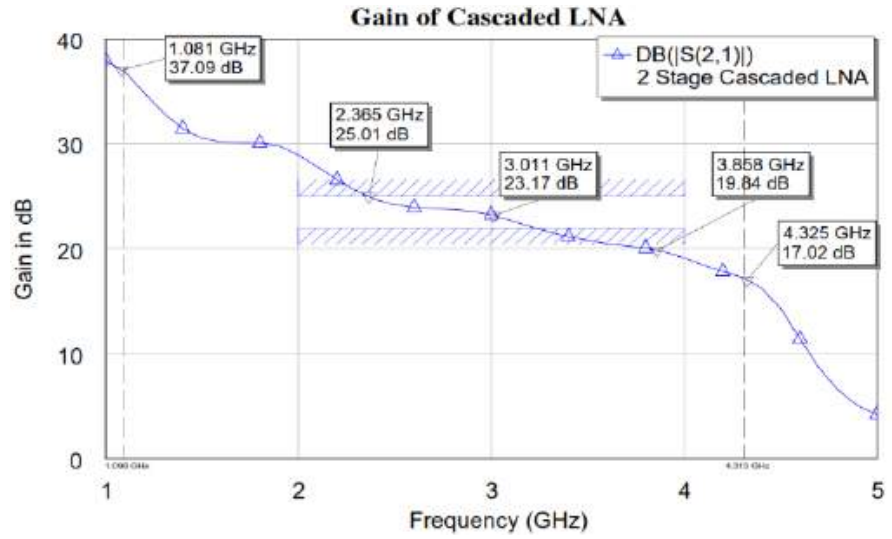

Figure 16. Shows Gain in $\mathrm{dB}$ of complete design of the proposed LNA design

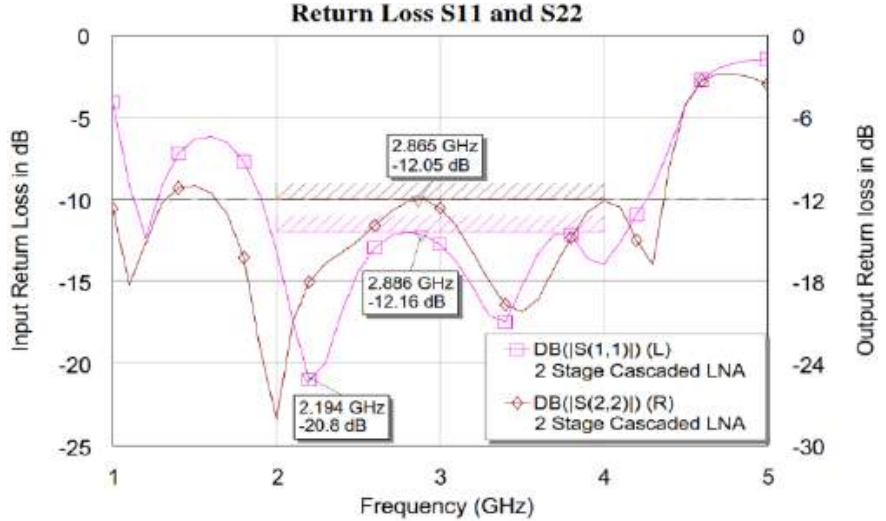

Figure 17. Shows Return loss at both Input and Output Port of the proposed LNA design

In the above figure 16 demonstrates the transducer gain (S21) which is having preferred esteem having more over $20 \mathrm{~dB}$ up to $4 \mathrm{GHz}$ however it is differing from $20 \mathrm{~dB}$ to $38 \mathrm{~dB}$. In the region of the interest between $2-4 \mathrm{GHz}$ it is having average of $23 \mathrm{~dB}$. Same lines figure 17 shows the very good return loss (S11 and S22) is less than -12dB between $2-4 \mathrm{GHz}$.

\section{CONCLUSION}

This work concludes that, with linear S-parameters measurements the nonlinear measurements likewise as critical part in the estimations of the LNA. In this proposed work, the attempt has made to address nonlinear and linear measurements to the wide band LNA with the assistance of rectangular display sort with basic estimations like linear measurements Gain, NF, RL and stability. The nonlinear measurements like AM-AM, AM-PM, Power spectrum, Power Gain and harmonics are simulated. The work gave the required information about LNA configuration by using different improvement estimation strategies and key qualities. Finally, author expounds and clarifies the linear, nonlinear estimations request of LNA design to acknowledge and work at microwave frequencies.

\section{ACKNOWLEDGMENT}

This work is upheld and maintained by MCT's Rajiv Gandhi Institute of Technology, Mumbai moreover authors might need to express appreciation toward Dr. Udhav Bhosle, Principal of RGIT, Chairman, IETE Mumbai division, for basic support and comfort for this investigation work. The authors may need to one of a kind an obligation of appreciation is all together for Mr. Manjunatha Reddy H. V Technical Manager, $\mathrm{RF}$ and $\mu \mathrm{W}$ division, Icon Design Automation Pvt. Ltd., and Dr. Krishna Venkatesh Jain University.

\section{REFERENCES}

[1] J. M. Collantes, J. Portilla, A. Anakabe and N. Otegi, "Characterization techniques for stability and noise in microwave amplifiers under largesignal excitations," 2016 IEEE MTT-S Latin America Microwave Conference (LAMC), Puerto Vallarta, 2016, pp. 1-3. doi: 10.1109/LAMC.2016.7851246 
[2] L. Pantoli, A. Barigelli, G. Leuzzi and F. Vitulli, "Analysis and design of a Q/V-band low-noise amplifier in GaAs-based $0.1 \mu \mathrm{m}$ pHEMT technology," in IET Microwaves, Antennas \& Propagation, vol. 10, no. 14, pp. 1500-1506, 1119 2016. doi: 10.1049/iet-map.2016.0422

[3] M. R. Beikmirza, A. Mohammadi and R. Mirzavand, "Power amplifier linearisation using digital predistortion and multi-port techniques," in IET Science, Measurement \& Technology, vol. 10, no. 5, pp. 467-476, 8 2016. doi: 10.1049/iet-smt.2015.0215

[4] J. Portilla and R. Jauregui, "Studies on AM and PM noise in microwave amplifiers working under linear and non-linear operating conditions," 2015 Asia-Pacific Microwave Conference (APMC), Nanjing, 2015, pp. 1-3. doi: 10.1109/APMC.2015.7411741

[5] O. Silva, I. Angelov, H. Zirath and N. Rorsman, "High linearity MMIC power amplifier design with controlled junction temperature," 2014 International Workshop on Integrated Nonlinear Microwave and Millimetre-wave Circuits (INMMiC), Leuven, 2014, pp. 1-3. doi: 10.1109/INMMIC.2014.6815096

[6] H. A. Ruotsalainen, N. Leder, H. Arthaber and G. Magerl, "Behavioral modeling of digital transmitters with time delay neural networks," 2014 IEEE MTT-S International Microwave Symposium (IMS2014), Tampa, FL, 2014, pp. 1-4. doi: 10.1109/MWSYM.2014.6848253

[7] J. B. Minkoff, "Wideband operation of nonlinear solid-state power amplifiers - Comparisons of calculations and measurements," in AT\&T Bell Laboratories Technical Journal, vol. 63, no. 2, pp. 231-248, Feb. 1984. doi: 10.1002/j.1538-7305.1984.tb00092.x

[8] V. Bridier et al., "Nonlinear measurement dedicated to non periodic pulse train for radar power amplifier characterization," 2014 IEEE MTTS International Microwave Symposium (IMS2014), Tampa, FL, 2014, pp. 1-4. doi: 10.1109/MWSYM.2014.6848400

[9] V. Bridier et al., "Nonlinear measurement of non periodic pulse train with mixer based NVNA dedicated to radar power amplifier," 2014 International Workshop on Integrated Nonlinear Microwave and Millimetre-wave Circuits (INMMiC), Leuven, 2014, pp. 1-3. doi: 10.1109/INMMIC.2014.6815076

[10] B. Brown, "Nonlinear Amplifier and Mixer Measurements with a Vector Network Analyzer," 32nd ARFTG Conference Digest, Tempe, AZ, USA, 1988, pp. 37-48. doi: 10.1109/ARFTG.1988.323915

[11] Pramod K B. and Kumaraswamy H V, "The Linear, Non-linear Measurements, Analysis and Evaluation for the Design of UltraWideband Low Noise Amplifier". International Journal of Computer Applications 158(6):22-26, January 2017.

[12] E. Godoy et al., "Time-Domain, Frequency Domain and non-linear measurements in neonates' Heart Rate Variability with clinical sepsis," Computing in Cardiology 2014, Cambridge, MA, 2014, pp. 429-432.

[13] D. Schreurs, "Applications of vector non-linear microwave measurements," in IET Microwaves, Antennas \& Propagation, vol. 4, no. 4, pp. 421-425, April 2010. doi: 10.1049/iet-map.2009.0479

[14] V. Teppati, A. Ferrero, V. Camarchia, A. Neri and M. Pirola, "Microwave measurements - Part III: Advanced non-linear measurements," in IEEE Instrumentation \& Measurement Magazine, vol. 11, no. 6, pp. 17-22, December 2008. doi: 10.1109/MIM.2008.4694153

[15] V. Camarchia, V. Teppati, S. Corbellini and M. Pirola, "Microwave Measurements Part II Non-linear Measurements," in IEEE
Instrumentation \& Measurement Magazine, vol. 10, no. 3, pp. 34-39, June 2007. doi: 10.1109/MIM.2007.4284255

[16] J. Dunsmore, "New methods \& non-linear measurements for active differential devices," IEEE MTT-S International Microwave Symposium Digest, 2003, Philadelphia, PA, USA, 2003, pp. 1655-1658 vol.3. doi: 10.1109/MWSYM.2003.1210456

[17] Y. Zhuo, H. Zhu and H. Xue, "Identifying a New Non-Linear CSI Phase Measurement Error with Commodity WiFi Devices," 2016 IEEE 22nd International Conference on Parallel and Distributed Systems (ICPADS), Wuhan, 2016, pp. 72-79. doi: 10.1109/ICPADS.2016.0019

[18] V. H. F. Brito et al., "Analysis of the influence of non-linear loads on the measurement and billing of electrical energy compared with the CPT," 2016 17th International Conference on Harmonics and Quality of Power (ICHQP), Belo Horizonte, 2016, pp. 617-622. doi: 10.1109/ICHQP.2016.7783332

\section{AUTHOR PROFILE}

Mr. Pramod K B Rangaiah was born in Mysore, Karnataka, India in 1989. He is currently working as Assistant Professor in MCT's RGIT, Mumbai and also working towards Ph.D. degree at JAIN University, Bangalore in Electronics Engineering. $\mathrm{He}$ received his B.E degree in Electronics and Communication from Dr. Ambedkar Institute of Technology, Bangalore Visvesvaraya Technological University in 2010, M.Tech degree in $\mathrm{R} F$ Communication from Jain University, Bangalore, in 2012 and He worked as $\mathrm{R} \mathrm{F}$ Design trainee at Icon Design and Automation Pvt LTD. and as visiting research es Design, Characterization And Optimization Of RF Passive Devices, Board Level Tuning And Optimization Of Matching Networks, Low Noise Amplifier, Power Amplifier, Circuit Linearization And High-Efficiency Design Techniques, Circuit Instability and Strategies.

Prof. Dr. Kumaraswamy H.V is currently working as Dean CAT in the Dept. of Telecommunication Engineering, RVCE, Bangalore. His research interests are Digital Signal Processing, Adaptive Signal Processing and Communication. He has got Ph.D. from Visvesvaraya Technological University for the research work on Smart antenna System using Dielectric lens. He is the author of the book titled "Signals \& Systems" Published by: Scitech Publication, Chennai, ISB No.8188429260.
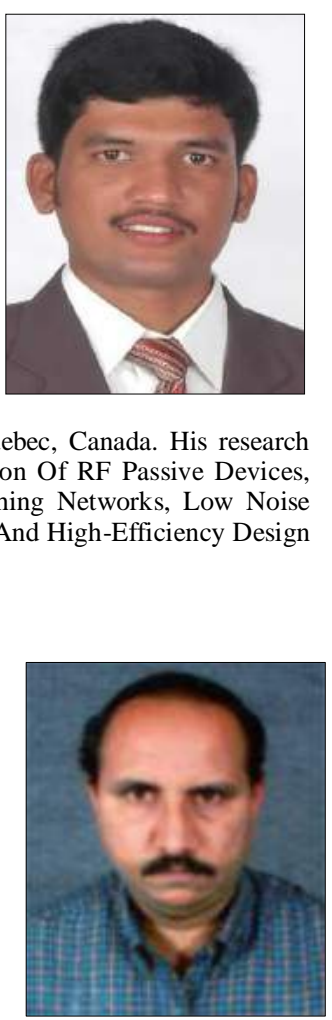

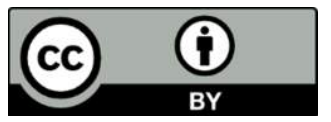

(C) 2017 by the author(s); licensee Empirical Research Press Ltd. United Kingdom. This is an open access article distributed under the terms and conditions of the Creative Commons by Attribution (CC-BY) license. (http://creativecommons.org/licenses/by/4.0/). 